LETTER TO THE EDITOR

\title{
Introducing a modified algorithm for enhanced operator independency in auditory steady-state responses (ASSR) testing
}

\author{
Presentazione di un algoritmo modificato per una maggiore indipendenza \\ dell'operatore nei test delle risposte uditive allo steady-state (ASSR) \\ Petros V. Vlastarakos ${ }^{1 *}$, John Plioutas ${ }^{2 *}$, Alexandros Delidis², Thomas P. Nikolopoulos² \\ ${ }^{1}$ ENT Dept., MITERA Infirmary, Athens, Greece; ' ENT Dept., Attikon University Hospital, Athens, Greece \\ P.V. Vlastarakos and J. Plioutas contributed equally to this work.
}

KEY WORDS: ASSR, hearing, algorithm, reliability, independency

PAROLE CHIAVE: ASSR, udito, algoritmo, affidabilità, indipendenza

Dear Editor,

Auditory steady-state responses (ASSR) are used to objectively assess the hearing thresholds of a given individual. Their value stems from reliably indicating the actual hearing levels (HLs) in four main frequencies $(500 \mathrm{~Hz}, 1000$ $\mathrm{Hz}, 2000 \mathrm{~Hz}, 4000 \mathrm{~Hz}$ ), by obtaining a valid estimated audiogram through the use of statistical measures ${ }^{1}$. Since mathematical prerequisites should be fulfilled in order for brainstem responses to be transformed into estimated HLs, ASSR are largely considered to be operator-independent.

Nevertheless, the "extended-time" value represents an operator-dependent parameter, which may relativise the independence of ASSR testing on the basis of the operator's experience or even wish. Indeed, the examination time is set to six minutes per examined frequency and HL in each ear. Whenever the stimulus curve reaches $100 \%$ certainty, it turns green (positive outcome) and the operator lowers the stimulus by $10 \mathrm{~dB}$. If the curve remains under $100 \%$ by the end of the examination time, the outcome is negative, yet the examiner may choose to extend the test by one minute, assuming that a positive outcome is likely to occur, and perform this time-extension repeatedly. This introduces an obvious intervention to the operator-independency of the test, with potential impact on the results obtained.

We propose a standardised operator-independent protocol regarding the "extended-time" value, in which, whenever the curve of the stimulus reaches $80 \%$ certainty, the testing time is extended by one minute once, and whenever the curve of the stimulus reaches $90 \%$ certainty (or above), the testing time is extended by one minute, for as long as the curve remains above $90 \%$, and stops, when the curve reaches $100 \%$ certainty, or drops below $90 \%$. The proposed protocol was tested in a cohort of 47 hearing-impaired individuals ${ }^{2}$ (age-range 14-85 years old ${ }^{3}$ ) in a soundproof chamber, with $40 \mathrm{~Hz}$ stimulus-rate CEchirp ${ }^{\circledR}$ sounds given through insert phones. The correlation between pure-tone audiometry (PTA) and ASSR measurements was performed using the intraclass correlation coefficient (ICC 1,1) (Tab. I). Statistical importance was accepted at the 0.05 level of significance.
Received: April 26, 2021

Accepted: June 14, 2021

Published online: November 26, 2021

Correspondence

Petros V. Vlastarakos

ENT Dept., MITERA Infirmary, Athens, Greece

E-mail: pevlast@hotmail.com

Funding

None.

Conflict of interest

The Authors declare no conflict of interest.

How to cite this article: Vlastarakos PV, Plioutas J, Delidis A, et al. Introducing a modified algorithm for enhanced operator independency in auditory steady-state responses (ASSR) testing. Acta Otorhinolaryngol Ital 2021;41:572-573. https://doi.org/10.14639/0392-100X-N1640

(c) Società Italiana di Otorinolaringoiatria e Chirurgia Cervico-Facciale

\section{(c) (1) $(9)$}

This is an open access article distributed in accordance with the CC-BY-NC-ND (Creative Commons Attribution-NonCommercial-NoDerivatives 4.0 International) license. The article can be used by giving appropriate credit and mentioning the license, but only for non-commercial purposes and only in the original version. For further information: https:// creativecommons.org/licenses/by-nc-nd/4.0/deed.en 
Table I. Correlation of ASSR estimates to actual PTA measurements.

\begin{tabular}{|c|c|c|c|c|}
\hline Ear & Frequency & ${ }^{*}$ PTA-ASSR & ${ }^{*}$ PTA-ASSR & $p$-value \\
\hline \multirow[t]{4}{*}{ Right } & $500 \mathrm{~Hz}$ & $0.922(0.86-0.96)$ & $0.875(0.78-0.93)$ & 0.075 \\
\hline & $1000 \mathrm{~Hz}$ & $0.901(0.83-0.95)$ & $0.829(0.71-0.90)$ & 0.021 \\
\hline & $2000 \mathrm{~Hz}$ & $0.904(0.83-0.95)$ & $0.845(0.74-0.91)$ & 0.049 \\
\hline & $4000 \mathrm{~Hz}$ & $0.917(0.85-0.95)$ & $0.895(0.82-0.94)$ & 0.384 \\
\hline \multirow[t]{4}{*}{ Left } & $500 \mathrm{~Hz}$ & $0.901(0.83-0.94)$ & $0.856(0.75-0.92)$ & 0.127 \\
\hline & $1000 \mathrm{~Hz}$ & $0.914(0.85-0.95)$ & $0.823(0.70-0.90)$ & 0.003 \\
\hline & $2000 \mathrm{~Hz}$ & $0.943(0.90-0.97)$ & $0.863(0.77-0.92)$ & 0.001 \\
\hline & $4000 \mathrm{~Hz}$ & $0.890(0.81-0.94)$ & $0.825(0.70-0.90)$ & 0.044 \\
\hline
\end{tabular}

WET: without extended time.

a correction factor according to the manufacturer specifications was applied in both protocols.

As shown in Table I, the ASSR results, obtained with the proposed algorithm, seem to reflect the PTA thresholds in a more accurate manner, compared to a protocol with no time-extension beyond the 6 minutes. Indeed, the correlation reliability in the proposed protocol was excellent in all frequencies of both ears, except $4000 \mathrm{~Hz}$ in the left ear which rated good, compared to the latter protocol, in which all frequencies had merely good correlation reliability ${ }^{4}$. The correlation differences between the two protocols were statistically significant in the frequencies of $1000 \mathrm{~Hz}$ and $2000 \mathrm{~Hz}$ in both ears, and $4000 \mathrm{~Hz}$ in the left ear. Interaural differences may be attributed to internal jittering caused by neurologic asynchronicity, and have also been described in the past ${ }^{5,6}$.

Hence, not only the results obtained with the proposed algorithm demonstrate closer correlation to the PTA thresholds, they also preserve the operator-independency of ASSR testing. Maintaining operator independency is inherent to the reliability of ASSR testing, irrespective of the potential nobility of the operator's motive to intervene.

\section{Ethical considerations}

The research protocol was submitted, and received ethical approval by the Ethics Committee of the University of Athens, prior to commencing data collection. Participants (or legal guardians) were asked to sign a consent form before being enrolled in the study.

\section{References}

1 Dimitrijevic A, John MS, Van Roon P, et al. Estimating the audiogram using multiple auditory steady-state responses. J Am Acad Audiol 2002;3:205-224.

2 Hosseinabadi R, Jafarzadeh S. Auditory steady-state response thresholds in adults with conductive and mild to moderate sensorineural hearing loss. Iran Red Crescent Med J 2014;17:e18029. https://doi. org/10.5812/ircmj. 18029

3 Pethe J, Mühler R, Siewert K, et al. Near-threshold recordings of amplitude modulation following responses (AMFR) in children of different ages. Int J Audiol 2004;43:339-345. https://doi. org/10.1080/14992020400050043.

4 Koo TK, Li MY. A guideline of selecting and reporting intraclass correlation coefficients for reliability research. J Chir Med 2016;15:155163. https://doi.org/10.1016/j.jcm.2016.02.012

5 Rabelo CM, Schochat E. Sensitivity and specificity of auditory steady-state response testing. Clinics (Sao Paulo) 2011;66:87-93. https://doi.org/10.1590/s1807-59322011000100016

6 Lins OG, Picton TW, Boucher BL, et al. Frequency-specific audiometry using steady-state responses. Ear Hear 1996;17:81-96. https:// doi.org/10.1097/00003446-199604000-00001 